7. Donner, P., Document type assignment accuracy in the journal citation index data of Web of Science. Scientometrics, 2017, 113, 219-236.

8. Gorraiz, J. and Schloegl, C., A bibliometric analysis of pharmacology and pharmacy journals: Scopus versus Web of Science. J. Inf. Sci., 2008, 34, 715-725.

9. Harzing, A.-W., Document categories in the ISI Web of Knowledge: Misunderstanding the social sciences? Scientometrics, 2013, 94, 23-34.

10. Sigogneau, A., An analysis of document types published in journals related to physics: Proceeding papers recorded in the Science Citation Index database. Scientometrics, 2000, 47, 589604.

11. Teixeira, M. C., Thomaz, S. M., Michelan, T. S., Mormul, R. P., Meurer, T., Fasolli, J. V. B. and Silveira, M. J., Incorrect citations give unfair credit to review authors in ecology journals. PLoS ONE, 2013, 8, e81871.

12. Miranda, R. and Garcia-Carpintero, E., Overcitation and overrepresentation of review papers in the most cited papers. J. Informetr., 2018, 12, 1015-1030.

13. Williams, R. and Bornmann, L., Sampling issues in bibliometric analysis. J. Informetr., 2016, 10, 1225-1232.

14. Yeung, A. W. K., Mocan, A. and Atanasov, A. G., Let food be thy medicine and medicine be thy food: a bibliometric analysis of the most cited papers focusing on nutraceuticals and functional foods. Food Chem., 2018, 269, 455-465.

15. Martínez, M., Herrera, M., López-Gijón, J. and Herrera-Viedma, E., H-Classics: Characterizing the concept of citation classics through $H$-index. Scientometrics, 2014, 98, 1971-1983.

16. Yeung, A. W. K., Bibliometric study on functional magnetic resonance imaging literature (1995-2017) concerning chemosensory perception. Chemosens. Percept., 2018, 11, 42-50.

17. Yeung, A. W. K., Goto, T. K. and Leung, W. K., The changing landscape of neuroscience research, 2006-2015: a bibliometric study. Front Neurosci., 2017, 11, 120.

18. Yeung, A. W. K., Goto, T. K. and Leung, W. K., At the leading front of neuroscience: a bibliometric study of the 100 most-cited articles. Front. Hum. Neurosci., 2017, 11, 363.

19. Yeung, A. W. K., Goto, T. K. and Leung, W. K., A bibliometric review of research trends in neuroimaging. Curr. Sci., 2017, 112, $725-734$.

20. Yeung, A. W. K., Heinrich, M. and Atanasov, A. G., Ethnopharmacology - A bibliometric analysis of a field of research meandering between medicine and food science? Front Pharmacol., 2018, 9, 215.

21. Yeung, A. W. K. et al., Dietary natural products and their potential to influence health and disease including animal model studies. Anim. Sci. Pap. Rep., 2018, 36, 345-358.

Received 20 November 2018; revised accepted 23 February 2019

doi: $10.18520 / \mathrm{cs} / \mathrm{v} 116 / \mathrm{i} 11 / 1909-1914$

\section{Improving groundwater recharge by ventilation of unsaturated zone}

\author{
V. K. Haritha and L. Elango* \\ Department of Geology, Anna University, Chennai 600 025, India
}

Groundwater recharge is affected by the entrapment of air in the unsaturated zone. During the infiltration process, air phase moves ahead of the wetting front and confined air mass resists wetting front propagation. This study aims at assessing the feasibility of improving groundwater recharge by providing ventilation in the unsaturated zone through the removal of entrapped air. In a laboratory sand column, ponded infiltration tests were carried out by providing vents of different diameters. Increase in diameter and number of vents improved the infiltration rate. Thus, simple pipes of any diameter inserted within the unsaturated zone beneath the recharge structures such as check dams, percolation ponds, surface spreading, etc. will lead to rapid increase in infiltration rate.

Keywords: Groundwater recharge, infiltration, unsaturated zone, ventilation.

THE ever-increasing dependence on groundwater to meet the water supply demand of the growing population, rising need for higher food production and industrial revolution has led to the depletion of groundwater resources and consequently the decline in water table. Over-exploitation of groundwater is a problem in several parts of the globe. In India, it is a serious issue and it has become difficult to sustain the boom in groundwater use $\mathrm{e}^{1,2}$. Other factors like erratic variation in annual rainfall, rapid urbanization and ill-maintained surface water bodies, have attributed to the drastic decrease in groundwater recharge. Changing climate and its subsequent impact on rainfall has also resulted in the reduction of groundwater recharge ${ }^{3}$. Extreme rainfall events are on the increase leading to increased runoff $^{4}$. To overcome the depletion of groundwater resources, several measures have been taken in various parts of the world. Groundwater recharge has been improved by implementing managed aquifer recharge (MAR) structures such as check dams, percolation ponds, rooftop rainwater harvesting, injection wells, etc. Construction of such MAR structures helps to increase the recharge by harvesting the rain water and reducing the runoff $^{5}$. The potential for increasing recharge by the implementation and planning of such rainwater harvesting structures has to continue and grow in India ${ }^{6-8}$. As per the 2013 master plan by the Central Groundwater Board $(\mathrm{CGWB})^{9}$ the estimated cost to artificially recharge an area of $941,541 \mathrm{~km}^{2}$ in India was INR 791,780 million. Thus, many MAR structures are being constructed in India to overcome groundwater depletion. But maintenance of

*For correspondence. (e-mail: elango34@hotmail.com) 

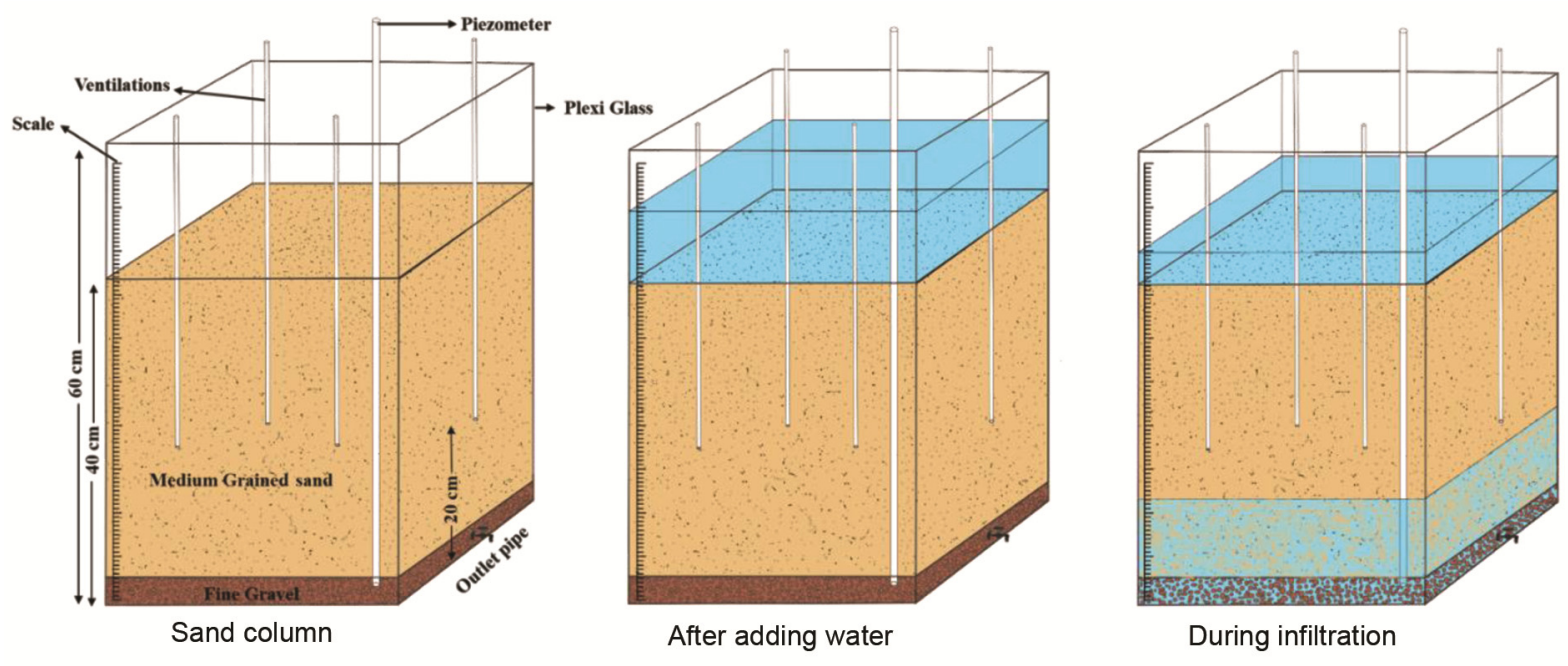

Figure 1. Experimental set up.

these structures and performance evaluation over time are seldom carried out. This hampers their efficiency especially after high intensity rains. This is because after heavy and short duration rainfall, large amount of water quickly gets accumulated in recharge structures, which leads to entrapment of air in the unsaturated zone beneath the wetting front that reduces the recharge.

Infiltration although an important component of flow processes in the unsaturated zone is complicated due to the presence of multiple phases of water, air and geological medium. The flow processes in this zone are extremely sensitive to variations in the proportion of fluid phases ${ }^{10}$. Spatial distribution of pore spaces in the unsaturated zone is crucial to fluid dynamics and these pores are the conduits providing path for infiltration ${ }^{11}$. When infiltration takes place, it displaces the air forward and this air moves ahead of the wetting front ${ }^{12-16}$. Entrapped air reduces the hydraulic conductivity and confined continuous air mass ahead of the wetting front, which resists the flow beneath the recharge structures ${ }^{17,18}$. In the present study, experiments are conducted to develop methods to address this problem by facilitating the removal of entrapped air for increasing the efficiency of recharge. Such experiments had been carried out earlier by removing the entrapped air at the base ${ }^{19,20}$ or at the sides of the columns $^{21,22}$. Though Horton ${ }^{23}$ conducted experiments by providing ventilating pipes at the top of the column for removal of entrapped air, they have not studied the effect of diameter and the increase in number of pipes. Earlier studies have focused on a single event approach ${ }^{17-27}$. Hence, the present study aims at assessing the feasibility of improving groundwater recharge by providing ventilation in the unsaturated zone by facilitating the removal of entrapped air and studying the impact of multiple ventilators and quantifing the effects on groundwater recharge.
An experimental setup consisting of a large square column made of acrylic material was used. The column dimensions were $40 \mathrm{~cm} \times 40 \mathrm{~cm} \times 60 \mathrm{~cm}$ (Figure 1). The column was closed at the bottom and open at the top. A tap was fixed close to the column base to facilitate draining of water. Fine gravel of size ranging from 2 to $4 \mathrm{~mm}$ was used to fill up to $4 \mathrm{~cm}$ from the bottom of the column. River sand was sieved using ro-tap test sieve shaker in which numbers 60 and 35 mesh size sieves were used in order to get 0.25 to $0.5 \mathrm{~mm}$ sand. This sand was used to fill the column to a height of $40 \mathrm{~cm}$ from the base. Sand of nearly uniform grain size was used to overcome problems related to fingering effect since the aim of this study is to understand the efficacy of soil ventilation. Top of the sand column was maintained flat by using a wood finish trowel. Water was initially added to wet the column and also to saturate the column beneath the outlet pipe. A thin plastic wire mesh was kept above the column to maintain a reasonably flat surface of the sand, and water was instantaneously added (in less than $3 \mathrm{sec}$ ) at the top and decline in water level was immediately measured. The water used to conduct the experiment had $700 \mathrm{mg} / 1$ total dissolved solids. A $55 \mathrm{~cm}$ long tube of $2 \mathrm{~cm}$ diameter was inserted up to the gravel bed with the bottom open. It functioned as piezometer for measuring the depth of the water table. The rise in water level in the piezometer tube was measured using a floating scale kept in the piezometer. The fall in water level was manually measured with a ruler fixed in the sand column. Time was measured using a stopwatch with an accuracy of $0.01 \mathrm{sec}$. First, an experiment was carried out to assess the infiltration rate without providing vents. Subsequently, in this column several experiments were carried out by ventilating the unsaturated part with pipes of 8, 12, 16 and $22 \mathrm{~mm}$ diameters. The number of ventilating pipes used was also varied from one to five. As a whole, 21 infiltration 

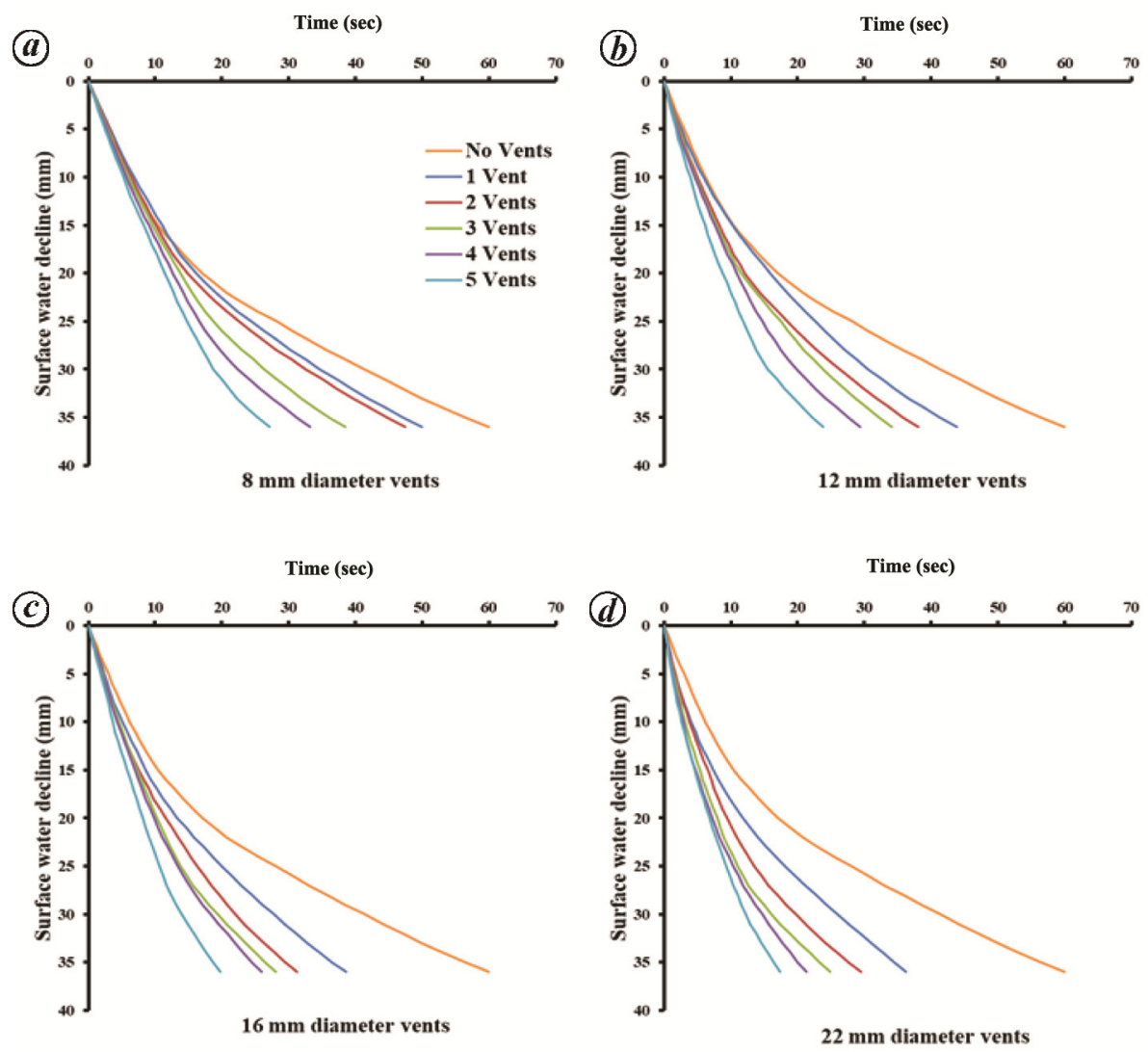

Figure 2. Decline in surface water level versus time with respect to diameter of vents.
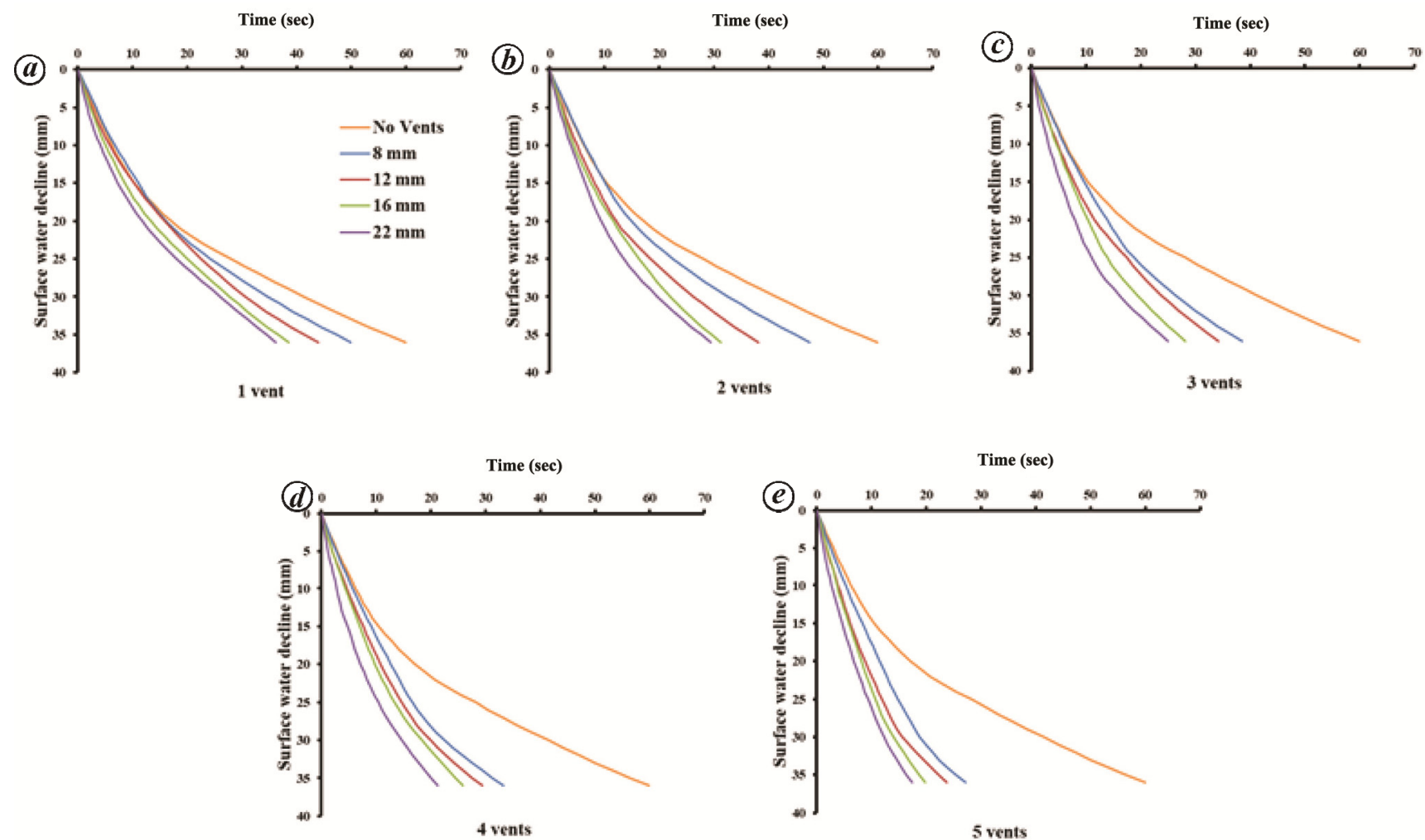

Figure 3. Decline in surface water level versus time with respect to number of vents. 
tests were carried out, one without providing any ventilation and 20 tests with ventilation. Every time, the experiment was continued till the saturated zone reached a level of $1 \mathrm{~cm}$ below the bottom of the vent. After every experiment, water was drained by opening the outlet pipe. It took about a day to drain the water before the next experiment could be conducted. Experiments were carried out by ponding the water to a height of $10 \mathrm{~cm}$ from the top of the sand column and the rate of decline in surface water level was noted down. From the time taken for the decline in water level, the cumulative infiltration rate was calculated. All experiments were conducted under room temperature. As all the experiments were conducted using the same quality of water, we assume that the viscosity and dissolved ions in the water may not have a major impact on the results. Further, all experiments were conducted during day time in February and March 2018 and hence the effect of temperature and viscosity would not have affected the experimental results.

Results of all the experiments conducted are shown as plots of time versus decline in water level with respect to the diameter of vents in Figure 2. Similar plots with respect to the number of vents are shown in Figure 3. In all these figures, decline in water level with time when vents are not provided is also shown. It is evident that the time taken for the decline in water level is always less compared to the experiment carried out without vents. Figure $2 a$ shows the relationship between water level decline and time for $8 \mathrm{~mm}$ diameter vent. When only one vent was used for a surface water decline of $36 \mathrm{~mm}$, it took $49.93 \mathrm{sec}$. When the number of vents was increased, the time taken for the corresponding decline in surface water level reduced. Similarly, Figure $2 b-d$ show the plots for 12, 16 and $22 \mathrm{~mm}$ diameter vents respectively. As the diameter of vents increased the time taken for the decline in water level reduced. Similarly, the time taken for surface water decline reduced with increase in the number of vents (Figure 3). However, there are some minor variations in the rate of decline as seen in the plots where the curves are not at an equal distance from each other. These may be due to some minor issues in the experimental procedure.

For a $36 \mathrm{~mm}$ decline in surface water level, without vents in the column, it took $59.93 \mathrm{sec}$. For $8 \mathrm{~mm}$ diameter with one vent, it took $49.93 \mathrm{sec}$. With two vents the time taken was $47.49 \mathrm{sec}$. With three, four and five vents, the time taken for infiltration was $38.5 \mathrm{sec}, 33.22 \mathrm{sec}$ and $27.19 \mathrm{sec}$ respectively. Similarly, experiments were repeated with the vents of diameter 12, 16 and $22 \mathrm{~mm}$ using one to five vents. When considering the time taken for $36 \mathrm{~mm}$ decline, for $12 \mathrm{~mm}$ diameter case, from one to five vents, the time taken was 43.89, 38.12, 34.16, 29.43 and $23.79 \mathrm{sec}$ respectively. Similarly, for $16 \mathrm{~mm}$ diameter vents, from one to five vents, it took 38.58, 31.26, 28.07, 25.91 and $19.76 \mathrm{sec}$ respectively. In the same way for the $22 \mathrm{~mm}$ diameter vents, from one vent to five vents, it took $36.24,29.45,24.95,21.3$ and $17.4 \mathrm{sec}$ respectively for $36 \mathrm{~mm}$ decline in surface water level.

The infiltration rate of water for different experiments was calculated. The experiment conducted without vents was $1.20 \mathrm{~mm} / \mathrm{s}$ for a surface water decline of $36 \mathrm{~mm}$ and for other experiments with vents, based on the time taken for $36 \mathrm{~mm}$, the decline in surface water level is given in Table 1. The infiltration rate increases with increase in number of vents. Similarly, the infiltration rate increases with the increase in the diameter of vents. Thus, the rate of infiltration was maximum for the experiment using 5 vents of $22 \mathrm{~mm}$ diameter.

The time taken for a rise in water level of the saturated zone by $20 \mathrm{~cm}$ without ventilation was $59.93 \mathrm{sec}$. The time taken for a similar rise for all experiments and the percentage increase in time with respect to the experiment without a vent are given in Table 2 .

From the table, it is clear that the percentage of increase with each experiment is progressive and there is a significant increase in infiltration with the increase in number and diameter of vents. For example, for 1 vent of $8 \mathrm{~mm}$ diameter, the increase in infiltration rate was $16.69 \%$ compared to the experiment without ventilation. The percentage of increase was about $54.63 \%$ for 5 vents of the same diameter. For 5 vents of $22 \mathrm{~mm}$ diameter, there was an increase of $70.97 \%$ compared to without ventilation.

In order to understand the benefits of vents, the time taken for the rise in saturated water level by $2.5,5,7.5$, $10,12.5$ and $15 \mathrm{~cm}$ of all the experiments was compared and is shown in Figure 4. The benefits of vents can be seen by the decrease in time taken for a rise in water level in the saturated column. Thus the experiments were carried out to confirm the advantages of providing simple pipes up to certain depth in the unsaturated zone. The depth to which the vents can be inserted needs to be less than the minimum expected thickness of the unsaturated zone. Greater the number and diameter of vents, higher will be the rate of recharge.

The experiment was carried out to study the effects of soil ventilation in improving the infiltration rate. The experimental results show a positive correlation with the number and size of vents used. For each individual set of experiment, with an increase in number and diameter of vents, there was a significant increase in infiltration rate.

Table 1. Measured infiltration rate for the experiments conducted

\begin{tabular}{lcccc}
\hline & \multicolumn{3}{c}{ Infiltration rate $(\mathrm{mm} / \mathrm{s})$ and vent diameter } \\
\cline { 2 - 5 } Number of vents & $8 \mathrm{~mm}$ & $12 \mathrm{~mm}$ & $16 \mathrm{~mm}$ & $22 \mathrm{~mm}$ \\
\hline 1 & 1.21 & 1.40 & 1.56 & 1.89 \\
2 & 1.29 & 1.64 & 1.82 & 2.20 \\
3 & 1.43 & 1.74 & 1.96 & 2.62 \\
4 & 1.57 & 1.92 & 2.05 & 2.94 \\
5 & 1.75 & 2.31 & 2.44 & 3.18 \\
\hline
\end{tabular}


Table 2. Time taken for $20 \mathrm{~cm}$ rise in water level and percentage increase compared to without soil ventilation in the column

\begin{tabular}{|c|c|c|c|c|c|c|c|c|c|c|}
\hline \multirow[b]{3}{*}{ Diameter of vents } & \multicolumn{10}{|c|}{ Time (sec) taken for $20 \mathrm{~cm}$ rise in water level with percentage $(\%)$ of increase } \\
\hline & \multicolumn{2}{|c|}{1 Vent } & \multicolumn{2}{|c|}{2 Vents } & \multicolumn{2}{|c|}{3 Vents } & \multicolumn{2}{|c|}{4 Vents } & \multicolumn{2}{|c|}{5 Vents } \\
\hline & Time & $\%$ & Time & $\%$ & Time & $\%$ & Time & $\%$ & Time & $\%$ \\
\hline $8 \mathrm{~mm}$ & 49.93 & 16.69 & 47.49 & 20.76 & 38.5 & 35.76 & 33.22 & 44.57 & 27.19 & 54.63 \\
\hline $12 \mathrm{~mm}$ & 43.89 & 26.76 & 38.12 & 36.39 & 34.16 & 43.00 & 29.43 & 50.89 & 23.79 & 60.30 \\
\hline $16 \mathrm{~mm}$ & 38.58 & 35.62 & 31.26 & 47.84 & 28.07 & 53.16 & 25.91 & 56.77 & 19.76 & 67.03 \\
\hline $22 \mathrm{~mm}$ & 36.24 & 39.53 & 29.45 & 50.86 & 24.95 & 58.37 & 21.3 & 64.46 & 17.4 & 70.97 \\
\hline
\end{tabular}

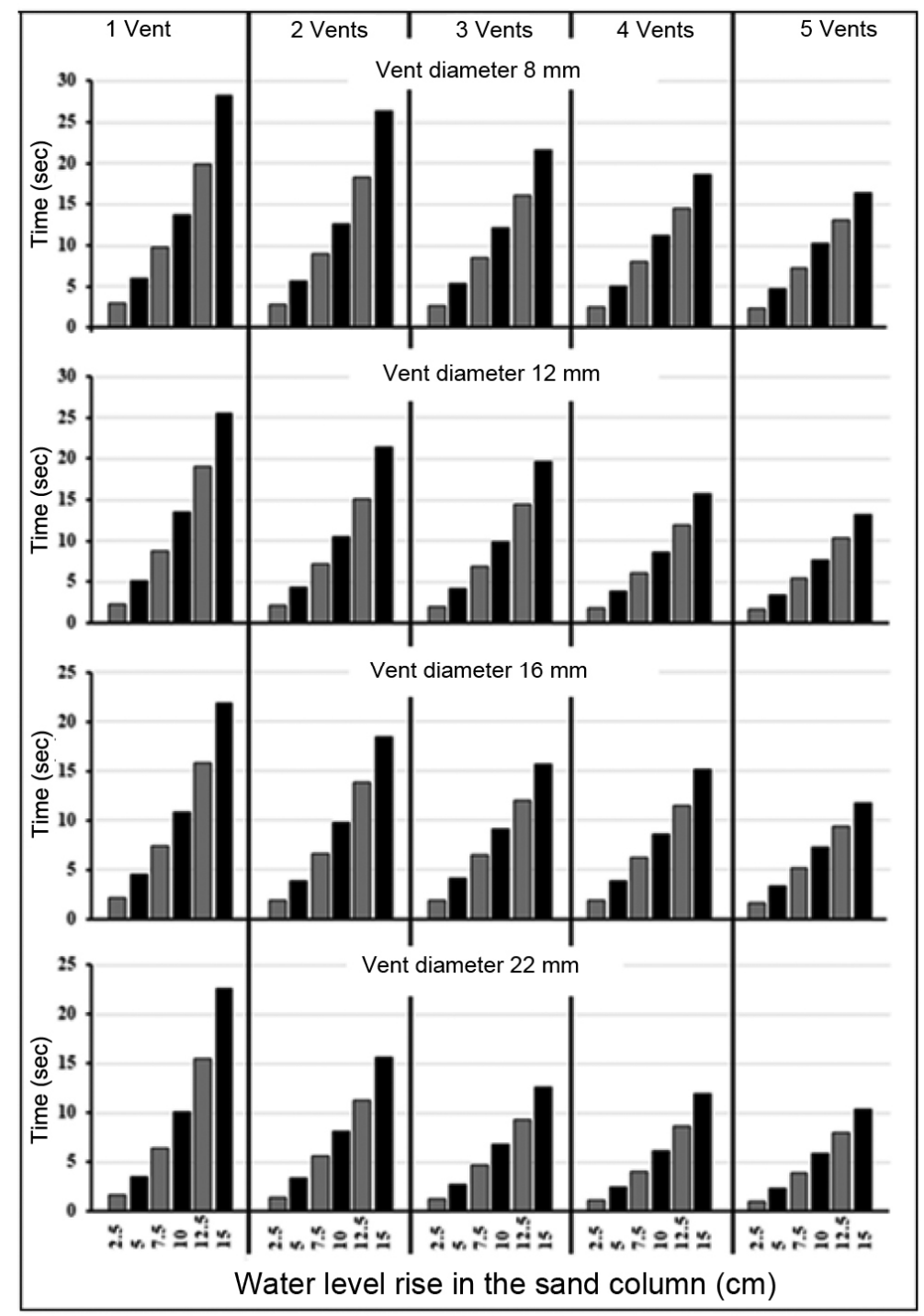

Figure 4. Time taken for water level rise in the sand column.

The corresponding rise in water level also showed an increasing trend with increase in number and diameter of vents. Hence, the study proves that the increase in number and diameter of vents improved the rate of groundwater recharge. Thus, the provision of simple pipes of any diameter inserted within the unsaturated zone beneath the recharge structures such as check dams, percolation ponds, surface spreading will lead to rapid increase in the infiltration rate. Such measures will be highly beneficial in improving the groundwater storage by harvesting a large amount of rainfall which otherwise would have gone as runoff during the extreme rainfall events. 
1. Gleeson, T., Wada, Y., Bierkens, M. F. P. and van Beek, L. P. H., Water balance of global aquifers revealed by groundwater footprint. Nature, 2012, 488, 197-200.

2. Shah, T., Roy, A. D., Qureshi, A. S. and Wang, J., Sustaining Asia's groundwater boom: an overview of issues and evidence. Nat. Resour. Forum, 2003, 27, 130-141.

3. Ferguson, G. and Gleeson, T., Vulnerability of coastal aquifers to groundwater use and climate change. Nat. Clim. Change, 2012, 2, $342-345$.

4. Gowrisankar, G. et al., Chemical, microbial and antibiotic susceptibility analyses of groundwater after a major flood event in Chennai. Sci. Data, 2017, 4, 170135.

5. Nättorp, A. et al., Overview of Managed Aquifer Recharge in India. In Natural Water Treatment Systems for Safe and Sustainable Water Supply in the Indian Context (eds Wintgens, T. et al.), IWA Publishing, London, UK, 2016, vol. 5, pp. 79-98.

6. Keller, A. A., Sakthivadivel, R. and Seckler, D. W., Water Scarcity and the Role of Storage in Development, Research Report Number 39. IWMI, Colombo, Sri Lanka, 2000.

7. Agarwal, A. and Narain, S., Dying Wisdom. Rise, Fall and Potential of India's Traditional Water Harvesting Systems. Centre for Science and Environment, New Delhi, 1997, 4, p. 404.

8. Shah, T., Gulati, A., Shreedar, H. P. G. and Jain, R. C., Secret of Gujarat's agrarian miracle after 2000. Econ. Polit. Wkly, 2009, 44, 45-55.

9. CGWB, Master Plan for Artificial Recharge to Groundwater. Report Central Ground Water Board, Ministry of Water Resources, Government of India, New Delhi, India, 2013.

10. Nimmo, J. R., Unsaturated zone flow processes. Encyclop. Hydrolog. Sci., 2005, 4, 2299-2322.

11. Kim, M., Jeong, G.-C., Chung, M. and Kim, N. W., Experimental assessment of the infiltration properties of a coarse soil medium in a dielectric infiltration test. Environ Geol., 2009, 57, 591-600.

12. Kuang, X., Jiao, J. J. and Li, H., Review on airflow in unsaturated zones induced by natural forcings, Water Resour. Res., 2013, 49, 6137-6165.

13. Bond, W. J. and Collis-George, N., Ponded infiltration into simple soil systems: 2. Pore air pressures ahead of and behind the wetting front. Soil Sci., 1981, 131, 263-270.

14. Adrian, D. D. and Franzini, J. B., Impedance to infiltration by pressure build-up ahead of the wetting front. J. Geophys. Res., 1966, 71, 5857-5862.

15. Dixon, R. M. and Linden, D. R., Soil air pressure and water infiltration under border irrigation. Soil Sci. Soc. Am. J., 1972, 36, 948-953.
16. Bond, W. J. and Collis-George, N., Ponded infiltration into simple soil systems: 1 . the saturation and transition zones in the moisture content profiles. Soil Sci., 1981, 131, 202-209.

17. Wang, Z., Feyen, J., Genuchten, M. Th. and Nielsen, D. R., Air entrapment effects on infiltration rate and flow instability. Water Resour. Res., 1998, 34, 213-222.

18. Touma, J. and Vauclin, M., Experimental and numerical analysis of two-phase infiltration in a partially saturated soil. Transp. Porous Med., 1986, 1, 27-55.

19. Faybishenko, B. A., Hydraulic behavior of quasi-saturated soils in the presence of entrapped air: laboratory experiments. Water Resour. Res., 1995, 31, 2421-2435.

20. Culligan, P. J., Barry, D. A., Parlange, J., Steenhuis, T. S. and Haverkamp, R., Infiltration with controlled air escape. Water Resour. Res., 2000, 36, 781-785.

21. Vachaud, G., Vauclin, M. and Khanji, D., Effects of air pressure on water flow in an unsaturated stratified vertical column of sand. Water Resour. Res., 1973, 9, 160-173.

22. Constantz, J., Herkelrath, W. N. and Murphy, F., Air encapsulation during infiltration. Soil Sci. Soc. Am. J., 1988, 52, 10-16.

23. Horton, R. E., An approach toward a physical interpretation of infiltration-capacity. Soil Sci. Soc. Am. J., 1941, 5, 399-417.

24. Free, G. R. and Palmer, V. J., Interrelationship of infiltration, air movement, and pore size in graded silica sand. Soil Sci. Soc. Am. J., 1941, 5, 390-398.

25. Parlange, J. Y. and Hill, D. E., Air and water movement in porous media: compressibility effects. Soil Sci., 1979, 127, 257-263

26. Ma, Y., Feng, S., Zhan, H., Liu X., Su, D., Kang, S. and Song, X., Water infiltration in layered soils with air entrapment: modified Green-Ampt model and experimental validation. J. Hydrol. Eng., 2010, 16, 628-638.

27. Grismer, M. E., Orang, M. N., Clausnitzer, V. and Kinney, K., Effects of air compression and counter flow on infiltration into soils. J. Irrig. Drain. Eng., 1994, 120, 775-795.

ACKNOWLEDGEMENTS. We acknowledge the Department of Science and Technology - Water Technology Initiative (DST-WTI, Grant: DST/TM/WTI/2K15/229 (G)) India and DST-INSPIRE fellowship (DST/INSPIRE Fellowship/2014/IF170066) for funding this research.

Received 3 August 2018; revised accepted 1 March 2019

doi: $10.18520 / \mathrm{cs} / \mathrm{v} 116 / \mathrm{i} 11 / 1914-1919$ 